\title{
PRODUÇÃO DE BIOMASSA E TEOR DE NUTRIENTES DO FEIJÃO-DE-PORCO (Canavalia ensiformis (L.) DC.) EM REFLORESTAMENTO NO ESTADO DO PARÁ
}

\author{
Breno Pinto Rayol ${ }^{1}$; Fabrízia de Oliveira Alvino-Rayol ${ }^{2}$. \\ Professor, Doutor da Universidade Federal do Oeste do Pará, bprayol@yahoo.com.br. \\ Professora, Doutora do Instituto Federal de Educação, Ciência e Tecnologia-Campus \\ Santarém, fabriziaalvino@yahoo.com.br
}

RESUMO: O objetivo deste estudo foi avaliar a produção de biomassa e teor de nutrientes do feijão-de-porco (Canavalia ensiformis (L.) DC.) consorciado com o paricá (Schizolobium parahyba var. amazonicum (Huber ex Ducke) Barneby) no estado do Pará. O feijão-de-porco foi semeado nas entrelinhas de paricá cultivado em espaçamento $4 \mathrm{~m} \times 4 \mathrm{~m}$. Foram observadas a produção de massa seca da parte aérea e a concentração de nutrientes do tecido vegetal das folhas do feijão- de-porco. A produção média de massas fresca e seca da parte aérea do feijãode-porco foi de 25,4 t.ha-1 e 4,8 t.ha-1, respectivamente. As concentrações médias de nutrientes contidas no tecido vegetal de feijão-de-porco foram: 44,26 g.Kg-1 (N); 3,01 g.Kg1 (P); 16,3 g.Kg-1 (K); 9,88 g.Kg-1 (Ca); 3,11 g.Kg-1 (Mg), 28 mg.Kg-1 (Cu); 61mg.Kg-1 (Mn); 175 mg.Kg-1 (Fe) e 41 mg.Kg-1 (Zn). Os resultados de produção de biomassa e de nutrientes da parte aérea do feijão-de-porco associado ao paricá revelam que esta espécie possui potencial para uso em adubação verde em áreas de reflorestamento.

PALAVRAS-CHAVE: cobertura morta, leguminosa de cobertura, nutrientes.

\section{BIOMASS PRODUCTION AND NUTRIENT CONTENT OF THE BEAN (Canavalia ensiformis (L.) DC.) IN REFORESTATION IN PARÁ STATE}

\begin{abstract}
The objective of this study was to evaluate biomass production and nutrient content of jack bean (Canavalia ensiformes (L.) DC.) as a green manure intercropped with paricá (Schizolobium parahyba var. amazonicum (Huber ex Ducke) Barneby). The experiment was carried out in an experimental area at the Vigia municipality (Pará state, Brazil). The jack bean was sown between rows of planted paricá spaced $4 \mathrm{mx} 4 \mathrm{~m}$. The plants were evaluated to shoot biomass production, nutrient contents in leaves of jack bean. Shoot fresh and dry biomass production of the evaluated specie were 25.4 t.ha ${ }^{-1}$ e 4.8 t.ha ${ }^{-1}$, respectively. The average concentrations of nutrients were $44.26 \mathrm{~g} . \mathrm{Kg}^{-1}(\mathrm{~N}) ; 3.01 \mathrm{~g} . \mathrm{Kg}^{-1}(\mathrm{P})$; 16.3 g. $\mathrm{Kg}^{-1}(\mathrm{~K}) ; 9.88 \mathrm{~g} \cdot \mathrm{Kg}^{-1}(\mathrm{Ca}) ; 3.11 \mathrm{~g} \cdot \mathrm{Kg}^{-1}(\mathrm{Mg}), 28 \mathrm{mg} \cdot \mathrm{Kg}^{-1}(\mathrm{Cu}) ; 61 \mathrm{mg} \cdot \mathrm{Kg}^{-1}(\mathrm{Mn})$; $175 \mathrm{mg} \cdot \mathrm{Kg}^{-1}(\mathrm{Fe})$ and $41 \mathrm{mg} \cdot \mathrm{Kg}^{-1}(\mathrm{Zn})$. The results of biomass productions and above-ground nutrients of jack bean show that this species has potential for use as green manure in agroforestry systems and reforestations areas.
\end{abstract}

KEY-WORDS: cover legumes, mulch, nutrients.

Entre as alternativas agroecológicas tecnicamente viáveis para aumentar ou manter o teor de matéria orgânica no solo encontra-se a adubação verde, que consiste na utilização de plantas em rotação, sucessão ou consorciação com as culturas, 
incorporadas ou não ao solo (CALEGARI et al., 1992). As plantas mais utilizadas como adubo verde são as leguminosas, pois, além de, fixarem nitrogênio atmosférico quando associadas aos rizóbios, promovem, ainda, a quebra do ciclo vegetativo das várias espécies que compõem a vegetação espontânea (BARRADAS, 2010).

A prática da adubação verde pode fazer parte do manejo integrado da vegetação espontânea, pois a fitomassa dos adubos reduz as populações de plantas invasoras

(SEVERINO;

HRISTOFOLETTI, 2001). Nos cultivos das espécies florestais Eucalyptus grandis e Eucalyptus saligna o uso de leguminosas de cobertura no controle integrado da vegetação espontânea apresentou as seguintes vantagens: melhoria das propriedades físico-químicas e microbiológicas do solo e aumento da capacidade de armazenamento de água no solo (FERREIRA NETO, 1994; BINKLEY et al. 1992).

Apesar das vantagens das leguminosas de cobertura, no Pará, ainda é incipiente o uso desses vegetais no manejo de solos, principalmente devido à carência de informações e à disponibilidade de sementes no comercio local (LOPES, 1998). Além disso, como a maioria dos benefícios da inclusão de adubos verdes em sistemas de culturas são constatados apenas a médio prazo, a adubação verde ainda é vista com reserva por muitos agricultores, estando restrita a um número reduzido de propriedades (SCIVITTARO et al., 2004)

Dentre as leguminosas de cobertura mais utilizada, o feijão-de-porco (Canavalia ensiformis (L.) DC.) vem se destacando. O potencial dessa espécie para fins de adubação verde, já foi relatado em vários trabalhos (Padovan, 2011; FERNANDES et al., 2007; FÁVERO et al. 2001) sendo a maioria associado a cultivos agrícolas (TEIXEIRA et al., 2005; HEINRICHS, R. et al., 2005).

Levando-se em consideração as características do feijão-de-porco e a escassez de trabalhos que abordam a sua associação com cultivos de espécies florestais nativas, este estudo teve como objetivo avaliar a produção de biomassa e teor de nutrientes dessa leguminosa de cobertura, para verificar seu potencial como adubo verde em área de reflorestamento com paricá no estado do Pará.

$\mathrm{O}$ experimento foi conduzido em área de reflorestamento sobre Latossolo Amarelo com as características químicas descritas na Tabela 1. A área de estudo está localizada no Município de Vigia distando 35 km da Rodovia PA-140, Nordeste do Estado do Pará $\left(00^{\circ} 51^{\prime} 12\right.$ " de latitude sul e $48^{\circ} 08^{\prime} 41$ de longitude oeste). 
Tabela 1. Características químicas do solo ( $0-20 \mathrm{~cm})$ da área estudada.

\begin{tabular}{|c|c|c|c|c|c|c|c|c|}
\hline $\mathrm{pH}$ & M.O & $P$ & $\mathrm{~K}$ & $\mathrm{Na}$ & $\mathrm{Ca}$ & $\mathrm{Ca}+\mathrm{Mg}$ & $\mathrm{Al}$ & $\mathrm{H}+\mathrm{Al}$ \\
\hline Água & $\mathrm{g} / \mathrm{Kg}$ & -- & $\mathrm{g} / \mathrm{dn}$ & ---ינ & 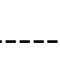 & ----Cmo & & \\
\hline 5,4 & 12,94 & 3 & 12 & 8 & 1,2 & 1,6 & 0,4 & 6,27 \\
\hline
\end{tabular}

A área foi roçada e preparada mecanicamente. As covas para o plantio do paricá foram abertas com auxílio de coveador mecânico. A fertilização foi realizada durante a fase de pré-plantio, utilizando-se adubo orgânico (esterco de ave) e químico (NPK- 18:18:18) nas proporções de $6 \mathrm{~L} \mathrm{cova}^{-1}$ e $150 \mathrm{~g} \mathrm{cova}^{-1}$, respectivamente.

O paricá foi semeado diretamente no campo no início do período chuvoso em janeiro de 2004, obtendo índice de germinação de $90 \%$ e as plantas com altura média de $2 \mathrm{~m}$ aos quatro meses de idade. A semeadura da leguminosa de cobertura foi realizada diretamente entre as plantas de paricá com auxílio de plantadeira manual, no final de maio de 2004, período adequado para a semeadura da mesma, no espaçamento de $0,5 \mathrm{~m} \times 0,5 \mathrm{~m}$.

No florescimento do feijão-de-porco, as plantas de oito amostras de $0,5 \mathrm{~m}^{2}$ foram cortadas rente ao solo e pesadas para a determinação da massa de matéria fresca. Em seguida, as amostras foram secas em estufa de ventilação forçada de ar a $65^{\circ} \mathrm{C}$, até atingirem massa constante, para quantificar a massa de matéria seca da parte aérea.

A análise de macronutrientes e micronutrientes de tecido vegetal foi realizada no Laboratório de Solos da Embrapa Amazônia Oriental no município de Belém.

A produção média de massas verde e seca de feijão-de-porco no floresciemnto, três meses após o plantio, foi de 25,4 t.ha- ${ }^{1}$ e 4,8 t.ha- $^{1}$, respectivamente. Dentre as sete leguminosas estudadas por Pereira (2001), o feijão-de-porco apresentou o melhor rendimento de massa seca da parte aérea. Essa espécie também se destacou nos trabalhos conduzidos por De-Polli e Chada (1989) e Favero et al. (2001). Neste último, o feijão-de-porco foi uma das leguminosas com maior produtividade média de matéria seca da parte aérea (5.371 kg.ha $\left.{ }^{-1}\right)$.

Para Fernandes et al. (2007) as controvérsias sobre os resultados a respeito da produção de massa seca de diferentes espécies vegetais, estão relacionadas, possivelmente, às condições ambientais em que tais experiências foram realizadas. 
Além das condições ambientais, a densidade de semeadura também pode afetar a produtividade de fitomassa das leguminosas. Segundo Fernandes et al. (1999), a produtividade de matéria seca de parte aérea do feijão-de-porco decresce com o incremento da densidade populacional dessa leguminosa.

A quantidade de nutrientes na matéria seca do feijão de porco semeado em solo classificado com Latossolo Amarelo, no município de Vigia é apresentada na Tabela 2. A quantidade de macronutrientes na fitomassa foi também estatisticamente maior nos tratamentos com feijão-de-porco em relação às demais espécies potenciais para adubação verde avaliadas por Heinrichs et al. (2005).

Tabela 2. Concentrações médias de macronutriente (N,P,K, Ca e $\mathrm{Mg})$ e micronutrientes $(\mathrm{Cu}$, $\mathrm{Mn}, \mathrm{Fe}$ e $\mathrm{Zn}$ ) contidas na matéria seca de feijão-de-porco, durante a floração aos dois meses de idade.

\begin{tabular}{ccccccccc}
\hline $\mathrm{N}$ & $\mathrm{P}$ & $\mathrm{K}$ & $\mathrm{Ca}$ & $\mathrm{Mg}$ & $\mathrm{Cu}$ & $\mathrm{Mn}$ & $\mathrm{Fe}$ & $\mathrm{Zn}$ \\
\hline 44,26 & 3,01 & 16,30 & 9,88 & 3,11 & 28 & 61 & 175 & 41 \\
\hline
\end{tabular}

Verifica-se na Tabela 1, que no tipo de solo utilizado, sendo o mesmo corrigido e adubado, a produção de biomassa do feijão-de-porco apresenta um potencial razoável de ciclagem de nutrientes no solo, evidenciando uma alternativa viável de médio a longo prazo para a recuperação e melhoria dos níveis de fertilidade do solo, principalmente quando usado por agricultores familiares com poder aquisitivo insuficiente para aquisição e uso de corretivos agrícolas e fertilizantes químicos.
Os resultados de produção de biomassa e de nutrientes da parte aérea do feijão de porco revelam que esta espécie de leguminosa possui potencial para uso em adubação verde em sistemas agroflorestais e reflorestamentos.

A falta de divulgação de resultados de pesquisa relacionados à adubação verde é uma das causas da pouca utilização de leguminosas nas propriedades rurais, desta forma, os resultados obtidos no presente trabalho representam um progresso nos estudos de produção de biomassa em áreas 
de reflorestamentos e sistemas agroflorestais, podendo também ser úteis nas escolhas de táticas de manejo de

\section{REFERÊNCIAS}

BARRADAS, C.A.A. Adubação Verde. Niterói: Programa Rio Rural, 2010. 10p. (Programa Rio Rural. Manual Técnico, 25).

BINKLEY, D.; DUNKIN， K. A.; DEBELL, D.; RYAN, M. G. Production and nutrient cycling in mixed plantations of Eucalyptus and Albizia in Hawaii. Forest Science, v.38, n.2, p.393-408, 1992.

CALEGARI, A.; ALCANTARA, P.B.; MIYASAKA, S.; AMADO, T.J.C. Caracterização Caracterização das principais espécies de adubo verde. In: CALEGARI, A.; MONDARDO, A., BULISANI, E.A., WILDER, L. DO P., COSTA, M.B.B. DA, ALCÂNTARA, P.B., MYASAKA, S., AMADO, T.J.C. Adubação verde no sul do Brasil. Rio de Janeiro: AS-PTA, 1992. p.277-280.

CARVAlHO, J. E. B. Manejo de solo e coberturas vegetais na cultura do mamoeiro em tabuleiros costeiros. Cruz das Almas: Embrapa Mandioca e Fruticultura. 2002. 4p. plantas invasoras que potencializem a preservação e melhoria das condições químicas e físicas dos solos.

DE-POLLI, H. CHADA, S.S. Adubação Verde incorporada ou em cobertura na produção de milho em solo de baixo potencial de produtividade. Revista Brasileira de Ciência do Solo, n.13, p.287-293, 1989.

FAVERO, C.; JUCKSCH, I.; ALVARENGA, R.C.; COSTA, L.M. Modificações na população de plantas espontâneas na presença de adubos verdes. Pesquisa Agropecuária Brasileira,. v. 36, n.11, p. 1355-1362, 2001.

FERREIRA NETO, P.S. Comportamento inicial do Eucalyptus grandis W. Hill ex Maiden em plantio consorciado com leguminosas na região do Médio Rio Doce, Minas Gerais. 1994, $78 \mathrm{f}$. Dissertação (mestrado) - Universidade Federal Viçosa, Viçosa, MG.

FERNANDES, M. F.; BARRETO, A.C.; EMÍDIO FILHO, J. Fitomassa de adubos verdes e controle de plantas daninhas em diferentes densidades populacionais de leguminosas. Pesquisa Agropecuária Brasileira, v.34, n.9, p.1593-1600, 1999. 
FERNANDES， J.C.; REZENDE， J.O.; DIAMANTINO, M.S.A.S.; REZENDE, V.J.R.P. ANTUNES, R.J.B. et al. Identificação de espécies para cobertura do solo e rotação de culturas no vale do Iuiu, Região Sudoeste da Bahia. Magistra, v.19, n. 2, p. 163-169, 2007.

HEINRICHS, R. VITTI, G.C.; MOREIRA, A.; FIGUEIREDO, P.A.M; FANCELLI, A.L.; CORAZZA, E.J. Características químicas de solo e rendimento de fitomassa de adubos verdes e de grãos de milho, decorrente do cultivo consorciado. Revista Brasileira de Ciência do Solo, v. 29, n. 1, p.71-79, 2005.

LOPES, O.M.N. Feijão-de-porco: Leguminosa para adubação verde $\mathrm{e}$ cobertura de solo. Belém: Embrapa Amazônia Oriental, 1998. 4p. (Recomendações Básicas, 37).

PADOVAN, M.P. et al. Acúmulo de fitomassa e nutrientes e estádio mais adequado de manejo do feijão-de-porco para fins de adubação verde. Revista Brasileira de Agroecologia. V.6, n.3, p.182-190. 2011.

TEIXEIRA, C. M. et al. Produção de biomassa e teor de macronutrientes do milheto, feijão-de-porco e guandu-anão em cultivo solteiro e consorciado. Ciência Agrotecnologia, v. 29, n. 1, p. 93-99, 2005.

PEREIRA, A. P. Identificação, caracterização e cinética de crescimento de leguminosas e gramíneas co alto poder relaticvo de penetração de raízes em solo coeso dos tabuleiros costeiros . 2001, 82f. Dissertação (mestrado) Universidade Federal da Bahia, Cruz das Almas, BA.

SCIVITTARO, W.B. et al. Dinâmica de Adubos Verdes no Sistema Solo-Planta. Pelotas: Embrapa Clima Temperado, 2004. 33p. (Documentos, 127).

SEVERINO, F.J.; CHRISTOFFOLETI, P.J. Banco de sementes de plantas daninhas em solo cultivado com adubos verdes. Bragantia, Campinas, v.60, n.3, p.201-204, 2001. 